\title{
Influence of amounts and particle diameter on the mechanical properties of several polymeric composites reinforced with GTR particles
}

\author{
Marc Marín-Genescà1, Jordi García-Amorós², Ramon Mujal-Rosass ${ }^{3}$, Lluís Massagués Vidal ${ }^{4}$, Xavier \\ Colom Fajula ${ }^{5}$
}

\begin{abstract}
${ }^{1}$ Mechanical Engineering Department, ETSEQ-URV, Països Catalans, 26, Tarragona - 43007 Spain, marc.marin@urv.cat

${ }^{2}$ Electrical Engineering Department, ETSE-URV, Països Catalans, 26, Tarragona - 43007 Spain, jordi.garciaamoros@urv.cat

3Electrical Engineering Department, EET-UPC, Colom,1 Terrassa - 08222 Spain, mujal@ee.upc.edu

${ }^{4}$ Mechanical Engineering Department, DEM-UPC, Colom,1 Terrassa - 08222 Spain, Xavier.salueña@upc.edu

${ }^{3}$ Chemical Engineering Department, EET-UPC, Colom,1 Terrassa - 08222 Spain, Xavier.colom@upc.edu
\end{abstract}

Correspondence: E-mail: marc.marin@urv.cat; Tel.: 0034977558777

\begin{abstract}
Nowadays, the massive use of tires generates large stocks of wasted material which is a serious environmental problem. The usual method used for processing wasted tires is the mechanical crushing, in which fiber, steel and rubber are separated. The aim of this research is the recycling of the obtained rubber, called also GTR (Ground Waste Tires). With this purpose, the paper analyses the mechanical properties of the composites produced by mixing GTR with several industrial polymers. These composites are characterized by the percentage of GTR in the composite and its particle size. These two variables along with seven industrial polymers, defines a set of composites from which the mechanical properties are analyzed and presented. From the results, it can be drawn that this proposal could be a way to enhance some polymer properties and to contribute in some way to reduce the environmental wasted tires problem
\end{abstract}

Keywords: GTR, Recycling, Reuse, Mechanical Properties, Composites, Materials

\section{Introduction}

The environmental problem of the accumulation of used tires [1-3] has driven the efforts of the scientific community to search solutions for recovery and reuse this used tires. In general, a thermoplastic or thermosetting polymer act as a matrix and the elastomer acts as a dispersed phase [4-6]. Moreover, as in other two-phase polymer blends, as composites [7-8], the interfacial compatibility between the components is important for achieving the desired properties. In the case of recycled elastomers, expected compatibility is low. One way to increase the compatibility between components is to reduce the degree of cross-linked GTR by devulcanization [9-11]. Significant changes in properties are observed when we change the size of the reinforcement particles [12]. The use of these GTR as reinforcements in composite materials has been widely studied in many works of physical characterization of polymers with particles of GTR, analyzing different composites, but never before specially a mechanical analysis and comparison of properties in different cases [13-19]. The presence of these in polymer matrix composite materials modifies mechanical behavior. The size of particles is restricted because of the pulverization technical procedures of GTR, so are chosen a simple and cheap way to obtain the classification in the three desired particle sizes $(<200 \mu \mathrm{m}, 200 \mu \mathrm{m}-500 \mu \mathrm{m}$ and $>500 \mu \mathrm{m})$. It is, therefore, to determine what percentage of GTR 
can be added to different polymers matrix (PVC, EVA, HDPE, PP, PA, ABS and PS), keeping mechanical properties, as well as the polymer initial microstructure [20-22] within an acceptable range of mechanical values, it could be a way to add GTR to various industrial processes. To this end, we have analyzed various concentrations of polymer/GTR (from $0 \%$ to $70 \%$ of GTR), with the three indicated particle sizes. The GTR constitutes the reinforcing agent here. Markov et al. [23] have observed that the presence of carbon black and fiberglass, as reinforcement in composite materials, increases the mechanical properties. Composite materials are heterogeneous, and their properties depend on the quantity, size and shape of the reinforcement, as well as other factors such as the preparation thereof, as well as compatibility. Saad et al. [24] have studied different samples of PVC with different compositions and variable proportions of additives such as carbon black (CB). The studies show that PVC with CB produces composites with good mechanical properties. In resume, the objectives of this research is to analyze and compare the mechanical behavior of different composite materials obtained by mixing different polymers with different percentages of GTR (up to 70\%), to see their response in function of the amount of GTR. Therefore the objective of this research is framed in the characterization and study of the mechanical properties of composite materials to use some of these compounds for the industry in general in order to give output to reusable materials to give a new application for the industry, in this way, the GTR would not serve in the applications of high requirements that polymers already have, but could give a part of the solution of recycling this materials.

\section{Materials and Methods}

\section{Methodology}

\subsection{Materials}

The next polymers were used in this study: PVC, polyvinyl chloride; high density polyetilene (HDPE) recycled from water bottles. The EVA (Etylene Vinyl Acetate) copolymer used is especially suitable for the production of films and extrusion coatings, (18\% of vinyl acetate and $82 \%$ ethylene). Polypropylene (PP), also in white color. White ABS, it is made up of $30 \%$ acrylonitrile, $20 \%$ butadiene, and $50 \%$ styrene. It is an amorphous thermoplastic material, highly resistant to impact. Polyamide 6 (PA), known as Nylon 6, is a transparent, hard and brittle solid. It is a semi-crystalline thermoplastic which has high strength, toughness and impact resistance. It shows good slip behavior and good wear resistance. Polystyrene, PS, (styrene-butadiene-styrene), solid, transparent, hard and brittle material. It is an amorphous thermoplastic, highly resistant to impact. On the other hand, the old used tire (GTR), with a particle size less than $700 \mu \mathrm{m}$, has verified by TGA analysis that carbon black content was about $35 \%$. The original GTR was separated by sieving into three categories of size particles: $<200 \mu \mathrm{m}, 200-500 \mu \mathrm{m}$ and $>500 \mu \mathrm{m}$. 
Table 1. Relevant data of the different Polymers used in the research

\begin{tabular}{|c|c|c|c|c|c|c|}
\hline $\begin{array}{l}\text { Polymer } \\
\text { Type }\end{array}$ & $\begin{array}{c}\text { Commercial } \\
\text { Name }\end{array}$ & $\begin{array}{c}\text { Fluidity Index } \\
\text { or } \\
\text { Melt Flow } \\
\text { Index (g/min) }\end{array}$ & $\begin{array}{l}\text { Density } \\
\left(\mathrm{kg} / \mathrm{m}^{3}\right)\end{array}$ & $\begin{array}{c}\text { Processing } \\
\text { Temperatur } \\
\text { e }\left({ }^{\circ} \mathrm{C}\right)\end{array}$ & $\begin{array}{c}\text { Melting } \\
\text { Temperature } \\
\left({ }^{\circ} \mathrm{C}\right)\end{array}$ & $\begin{array}{c}\text { Pressing } \\
\text { Temperature } \\
\left({ }^{\circ} \mathrm{C}\right)\end{array}$ \\
\hline PVC & Etinox & 1.35 & 1.225 & $195-200{ }^{\circ} \mathrm{C}$ & $200^{\circ} \mathrm{C}$ & $210^{\circ} \mathrm{C}$ \\
\hline EVA & $\begin{array}{l}\text { Alcudia PA } \\
539 \text { type }\end{array}$ & 0.20 & 937 & $105-110^{\circ} \mathrm{C}$ & $110^{\circ} \mathrm{C}$ & $120^{\circ} \mathrm{C}$ \\
\hline HDPE & $\begin{array}{l}\text { Alcudia } \\
\text { 4810-B }\end{array}$ & 1.35 & 960 & $150-155^{\circ} \mathrm{C}$ & $155^{\circ} \mathrm{C}$ & $170^{\circ} \mathrm{C}$ \\
\hline PA 6 & $\begin{array}{r}\text { Ultramid } \\
\text { B3S }\end{array}$ & 1.55 & 1130 & $195-200^{\circ} \mathrm{C}$ & $220^{\circ} \mathrm{C}$ & $210^{\circ} \mathrm{C}$ \\
\hline ABS & $\begin{array}{c}\text { Terluran® } \\
\text { HH-106 }\end{array}$ & 1.45 & 1050 & $180-185^{\circ} \mathrm{C}$ & $230^{\circ} \mathrm{C}$ & $195^{\circ} \mathrm{C}$ \\
\hline PP & $\begin{array}{l}\text { Isplen }{ }^{\circledR} 099 \\
\text { K2M type }\end{array}$ & 0.55 & 902 & $155-165^{\circ} \mathrm{C}$ & $165^{\circ} \mathrm{C}$ & $165^{\circ} \mathrm{C}$ \\
\hline PS & $\begin{array}{r}\text { Polystyrol } \\
486 \mathrm{M}\end{array}$ & 1.45 & 1050 & $180-185^{\circ} \mathrm{C}$ & $180^{\circ} \mathrm{C}$ & $195^{\circ} \mathrm{C}$ \\
\hline
\end{tabular}

\subsection{Preparation of the compound}

Once separated into 3 categories, the particles of GTR, the recycled tire powder was dried in an oven at $100^{\circ} \mathrm{C}$ for $24 \mathrm{~h}$. Five samples of Polymer/GTR compound, varying the composition $(5 \%, 10 \%, 20 \%, 40 \%$, $50 \%$ and $70 \%$ of GTR), were prepared for each particle size. The mixing process was done with a Brabender mixer machine, at different temperatures. Polymer/GTR laminates were obtained by using a hot plates press at constant pressure 200 bar and different temperatures for $10 \mathrm{~min}$ depending on the polymer to be treated. Samples for testing were properly set up according to the specifications of ASTM-D-638 type V. A sample of the pure polymer was also prepared with the same requirements in order to obtain comparable results.

\subsection{Mechanical Analysis}

Stress-strain tests were carried out with an Instron 3366-10 kN universal machine, following the specifications of ASTM-D-638 type V. The test speed was $20 \mathrm{~mm} / \mathrm{min}$. The test temperature was $23 \pm 2^{\circ} \mathrm{C}$, and the relative humidity was of $50 \pm 5 \%$. The study of mechanical properties, according to the GTR concentration in the matrix and the particle sizes include the young's modulus, tensile stress, elongation at break and toughness. Five specimens for testing were used. The mean and standard deviation were calculated for each magnitude, leaving out of account those samples with such a result that was proved to be defective.

\section{Results and discussion}

\subsection{Mechanical Properties}

This part shows the results by testing the stress-strain mechanical properties of different polymers are analyzed with different GTR concentrations and the three categories of sizes of reinforcing particles in the Polymer matrix. Below are following the figures of mechanical properties graphs in function of percent of GTR contents and the particles size. 


\subsubsection{Mechanical behavior of PVC/GTR Composites}

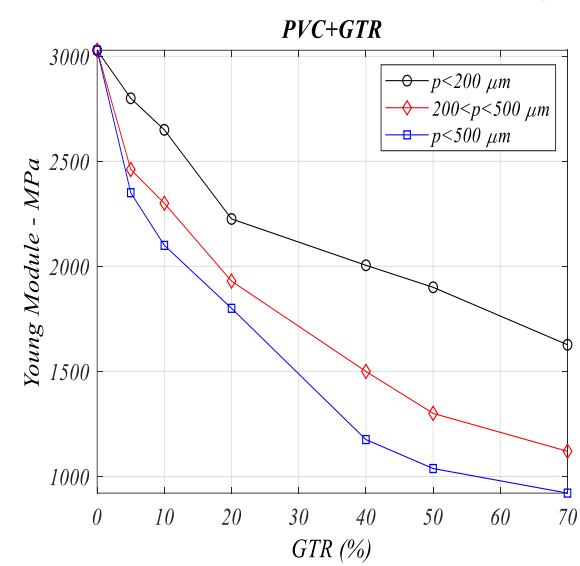

(a)

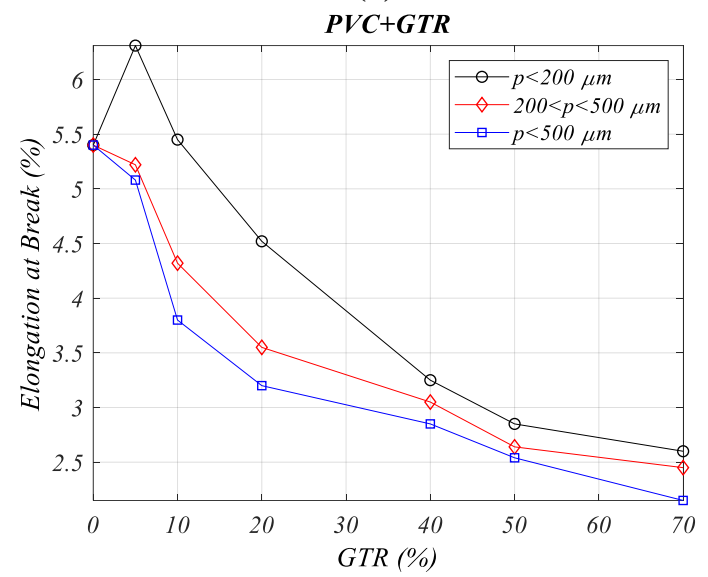

(c)

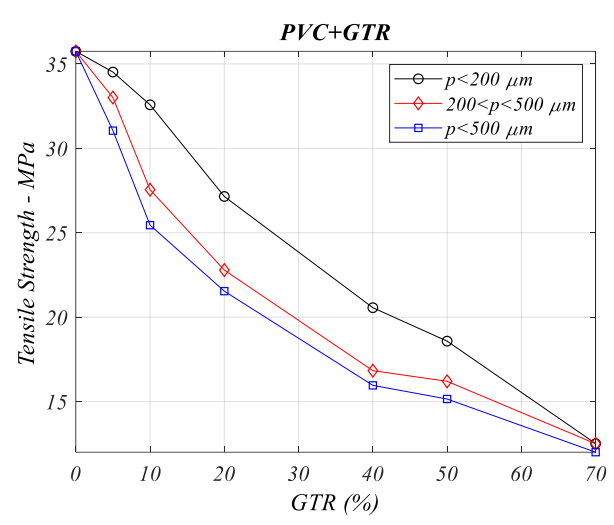

(b)

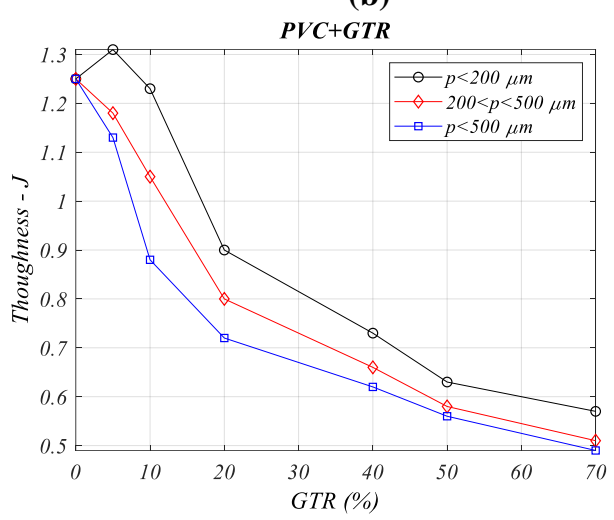

(d)

Figure 2. a) Young's modulus (MPa), b) Tensile Stress (MPa), c) Elongation at break (\%),d) Toughness (J), for different concentrations of PVC/GTR and particles sizes.

Figure 2-a shows the Young's Modulus of the composite, in which we see that values decrease as filler is added the rigidity for small GTR concentrations $(>10 \%)$ decreases significantly regarding the original PVC, from a value of $2800 \mathrm{MPa}(5 \%$ GTR) to $1627 \mathrm{MPa}(70 \%$ GTR) for lowest particle sizes $(<200 \mu \mathrm{m})$. We can also see how rigidity decreases with the other particle sizes, from original Young's modulus value of $2461 \mathrm{MPa}(5 \%$ GTR) to $1120 \mathrm{MPa}(70 \%$ GTR) for particle size of $200-500 \mu \mathrm{m}$, and to $921 \mathrm{MPa}$ for particle size of $>500 \mu \mathrm{m}$ for the same GTR concentration. This is due to the fact that large particles have higher probability of cracks, and they also crowd during the melting process. When the content of GTR continues to increase, interfacial adhesion is weakened, and it causes a diminution of stiffness in all the cases. Thus, for concentrations of $40 \%$ and $50 \%$ GTR, values are $2005 \mathrm{MPa}$ and $1900 \mathrm{MPa}(28.4 \%$ and $32.14 \%$ lower than those of the EVA/GTR-5\% compound for $<200 \mu \mathrm{m}$ particles -Figure 2.a-), reaching slightly higher values than those of pure PVC for 70\% GTR concentrations, no matter the size of the particles is. Figure 2(b), shows Tensile Strength shows , for low GTR concentrations (5-10\%) and small particle sizes, the strength value practically does not change, whereas beyond higher concentrations $(20 \%)$ the values show a pronounced fall-off, which demonstrates the poor compatibility between the components as the percentage of reinforcement is increased or also the particle size. Elongation at break property (Figure 2(c)), for small sized GTR particles (shows good adhesion) and low concentrations (5\%), elongation is greater than even that of pure PVC, the compound showing increased elasticity. As the concentration increases, maintaining particle size, values decrease slightly with $10 \%$ GTR values similar to PVC, whereas this decrease is greater after concentrations of $20 \%$, stabilizing at high concentrations (40-50\%). For medium or large-sized particles, increases in GTR concentration always produce reductions in elongation, showing the bad adhesion that these sizes of particle display in the matrix. Figure 2(d) shows the Toughness property that the behavior of different sizes of GTR 
particles differ substantially, since for small sized particles and low concentrations (5\%), the compound shows good adhesion and an improvement in mechanical properties, whereas for medium and large particles integration is bad from the outset, reducing the value of breakage energy even with GTR concentrations of $5 \%$.

Therefore, the fragility brought to the compound by adding the reinforcement particles worsens its mechanical properties from the outset, as it has been observed in other polymer-GTR compounds. For high GTR concentrations, the behavior is poor in all circumstances, without concern for particle size.

\subsubsection{Mechanical behavior of EVA/GTR Composites}

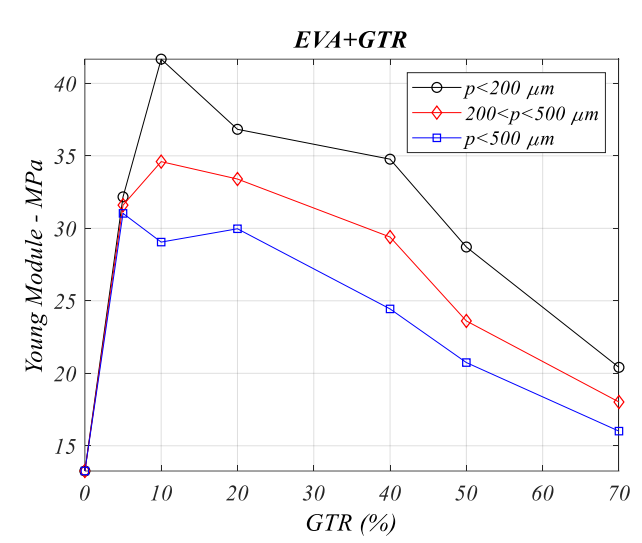

(a)

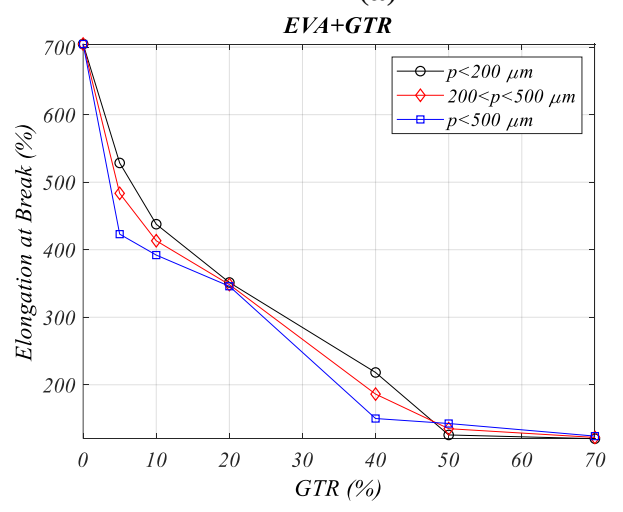

(c)

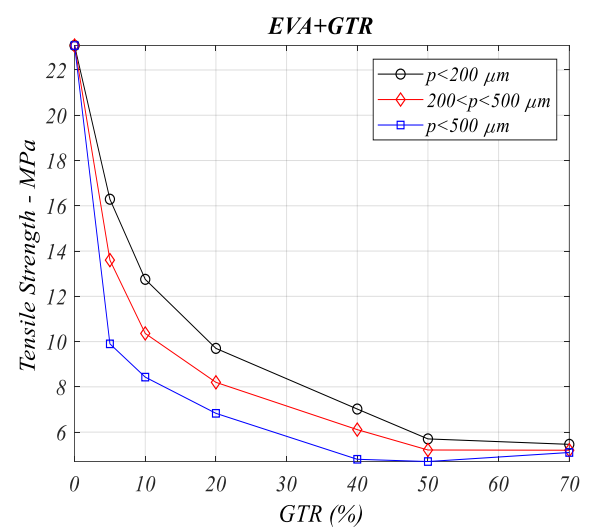

(b)

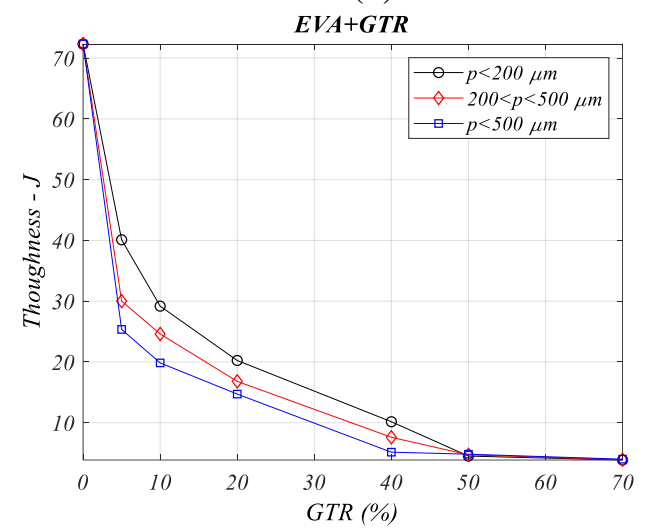

(d)

Figure 3. a) Young's modulus (MPa), b) Tensile Stress (MPa), c) Elongation at break (\%), d) Toughness (J), for different concentrations of EVA/GTR and particles sizes.

As it can be seen in Figure 3(a), Young's Modulus of the composite is greatly increased for low GTR concentrations $(10 \%)$ regarding to the original EVA, from a value of 13.2 to $41.7 \mathrm{MPa}$ for small particle sizes $(<200 \mathrm{~mm})$. We can also see how rigidity increases with the other particle sizes, from original Young's modulus value of 13.2 to $34.6 \mathrm{MPa}$ for particle size range of $200-500 \mathrm{~mm}$, and to $29 \mathrm{MPa}$ for particle size of $>500 \mathrm{~mm}$ for the same GTR concentration. This is due to the fact that large particles have higher probability of cracks, and they also crowd during the melting process. When the content of GTR continues to increase, interfacial adhesion is weakened, and it causes a diminution of stiffness in all the cases. Thus, for concentrations of $40 \%$ and $50 \%$ GTR, values are 34.8 and $28.7 \mathrm{MPa}(17 \%$ and $30 \%$ lower than those of the EVA/GTR-10\% compound) for $<200 \mathrm{~mm}$ size particles. Figure 3(b) shows the Tensile Stress, can see a decrease since low GTR concentrations. Thus, for $5-10 \%$ GTR concentrations, the decrease of tensile stress compared to pure EVA is quite significant, from 23 to $16.2 \mathrm{MPa}$ and to $12.7 \mathrm{MPa}$ ( $28 \%$ and $44 \%$, respectively, for particle size $<200 \mu \mathrm{m})$. These decreases are more significant for larger particle sizes. From 20\% GTR, values fall sharply regardless of particle size or GTR concentration in the matrix. It shows poor compatibility between components when the percentage of reinforcement is 
increased. The addition of old used tire particles in all compounds produces a decrease in the Elongation at Break (Figure 3(c)) and Toughness (Figure 3(d)). For particle size $<200 \mu \mathrm{m}$, elongation at break of the GTR compounds [25] goes from $704 \%$ to $528 \%, 437 \%$, and $351 \%$, which means decreases of $29 \%$, $43 \%$, and $50 \%$ for GTR concentrations of $5 \%, 10 \%$, and $20 \%$. The decrease in elongation at break is related to the imperfect interfacial adhesion between components. The incidence of poor adhesion between phases is a particularly important result. The reduction of deformation capacity of the elastomer influences the decrease in elongation and, subsequently, the decrease of hardness. Regarding toughness (Figure 3(d)), these drops are even greater, regarding the compound with the smallest particle size $(<200 \mathrm{~mm})$, the toughness goes from $72.3 \mathrm{~J}$ for pure EVA to $40 \mathrm{~J}$ or $29.2 \mathrm{~J}$ for $5 \%$ and $10 \%$ GTR concentrations. It will decrease even more for larger particle sizes and for concentrations above $20 \%$. So the optimum particle size is the $\mathrm{p}<200 \mu \mathrm{m}$. The addition of GTR decrease the mechanical properties analyzed [26].

\subsubsection{Mechanical behavior of PP/GTR Composites}

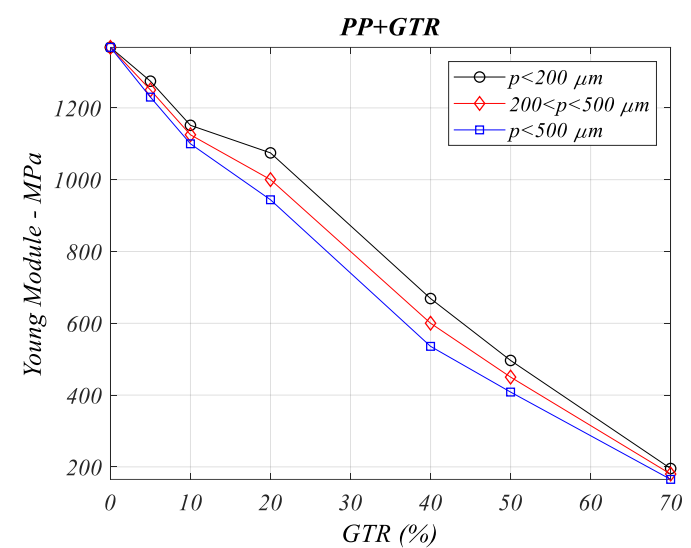

(a)

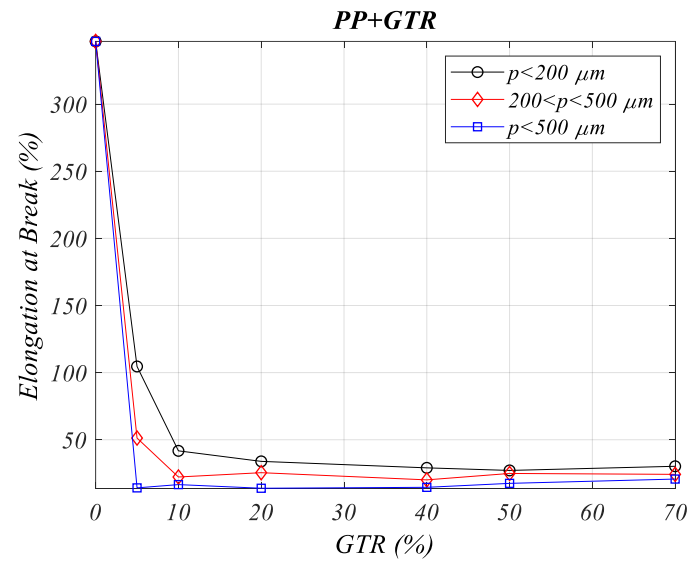

(c)

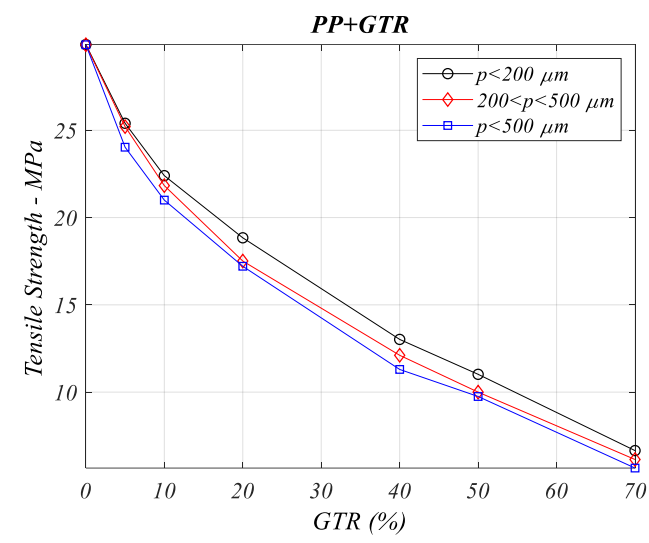

(b)

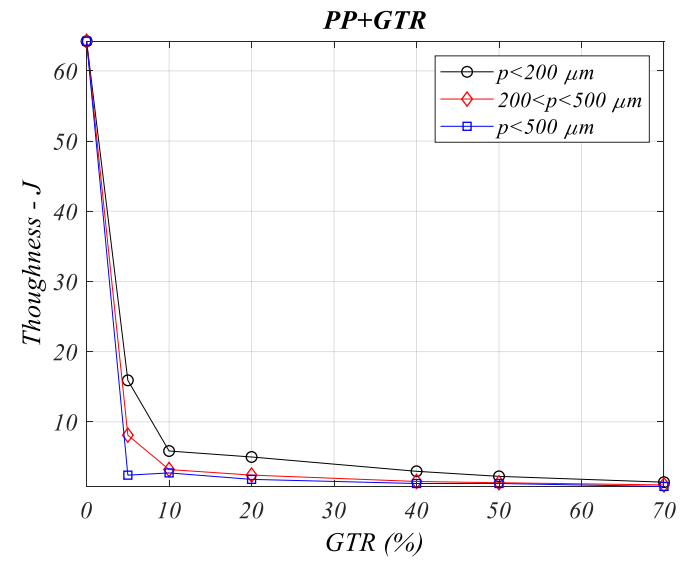

(d)

Figure 4. a) Young's modulus (MPa), b) Tensile Stress (MPa), c) Elongation at break (\%), d) Toughness (J), for different concentrations of PP/GTR and particles sizes

Figure 4-a shows the Young Modulus, it's observed that the values decrease as GTR fill is added. The behaviour of the compounds, however, is different as the concentration of the GTR in the matrix varies. Thus, for small concentrations of GTR $(5 \%, 10 \%$ and $20 \%)$, which decreases slightly for particles <200 $\mu$ m. For higher GTR concentrations (40\%, 50\% and $70 \%$ ) and the same size of the particles, the decreases are more and with differences according to the different particle sizes. This behaviour, is due to the fact that the cohesion of the interface with the particles is slight, with cracks and fractures that weaken the mechanical properties. Figure 4-b shows tensile strength, where the tension is more uniform and linear, and with values lower than those of pure PP polymer. On the other hand, the differences between the different particle sizes are insignificant, since they are around $5 \%$ to $15 \%$ when comparing the extremes. This means that when the content of reused tires increases, the interfacial 
adhesion weakens, causing a decrease in rigidity in all cases, regardless of particle size. In addition, the possibility of agglomeration of the particles during the compound mixing process must be considered.

The addition of reused tire particles in all the compounds produces a remarkable decrease in the Elongation at Break (Figure 4-c) and Toughness (Figure 4-d). The tenacity and elongation at break in compounds with GTR gives much lower values than the pure PP matrix (for the case of PP $+70 \%$ GTR about 9 times lower elongation relative to breakage, and 12 times lower relative hardness). The decrease in elongation at break is related to the imperfect adherence of the interface between the components.

\subsubsection{Mechanical Behavior of HDPE/GTR Composites}

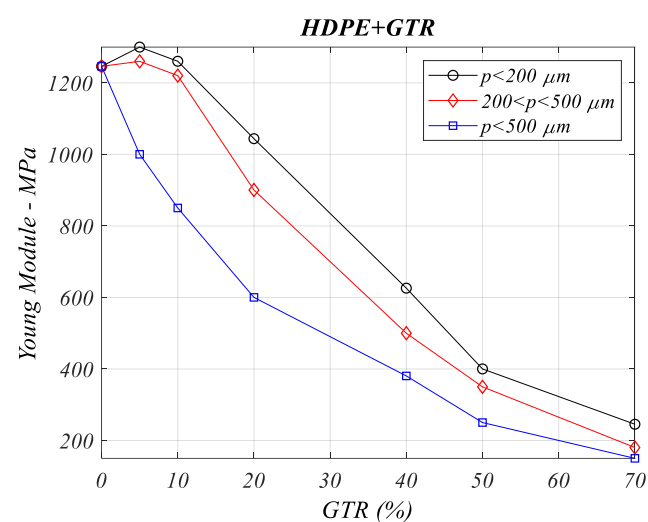

(a)

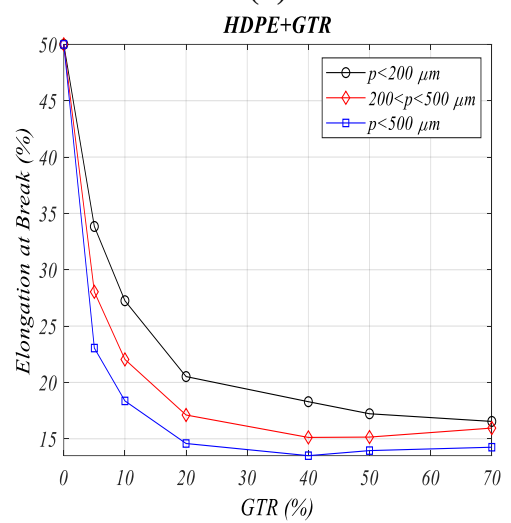

(c)

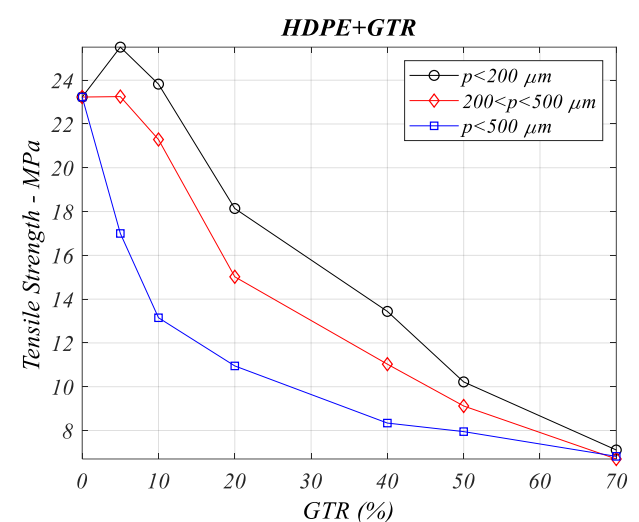

(b)

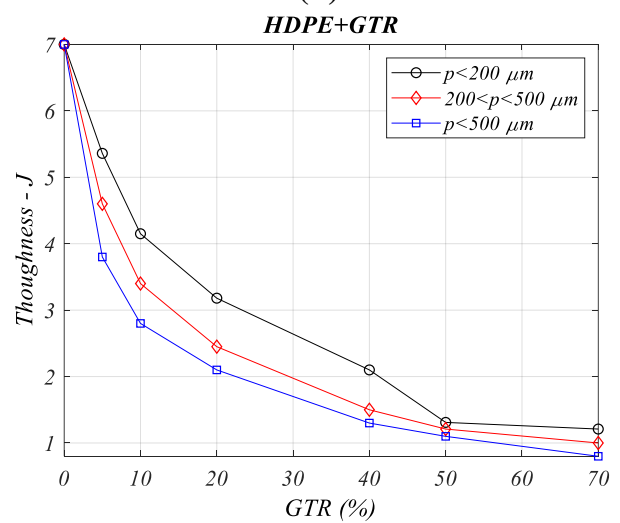

(d)

Figure 5. a) Young's modulus (MPa), b) Tensile Stress (MPa), c) Elongation at break (\%), d) Toughness $(\mathrm{J})$, for different concentrations of HDPE/GTR and particles sizes

Figure 5(a) shows the compound's Young's Modulus in which, the rigidity is seen (for concentrations of up to $10 \%$ GTR) to increase with regard to the original HDPE (5-8\%) for small-sized particles ( $<200 \mathrm{~mm}$ ) and stays practically the same for particles between 200 and $500 \mathrm{~mm}$. This is due to the fact that the composite materials with large particles have a great probability to reduce the interaction in the interphase and the poor adhesion generates that the propagation of some fissure take place very easy. This is obvious in the case of particles over $500 \mu \mathrm{m}$, which shows a significant decrease in values of mechanical properties in all the cases studied (decreases of 20$35 \%$ for concentrations of $5-10 \%$, respectively). When the content of the reused tires increases, interfacial adhesion weakens causing a decrease in rigidity in all cases, no matter the particle size. For concentrations of $40 \%$ and $70 \%$ GTR, the values are three and five times less than those of the pure HDPE. On the other hand the addition of reused tire particles in all the compounds produces a notable decrease of elongation at break (Figure 5-b) in the HDPE composites with GTR, can check that the decrease is so high for the 5\% GTR compounds, for HDPE/GTR-5\%, we have this values $33.84 \%$ for $200 \mu \mathrm{m}$ size of GTR particles, $28.04 \%$ for $200-500 \mu \mathrm{m}$ of size, and $23.05 \%>500 \mu \mathrm{m}$, this probes that the decrease is $18 \%$ and $32 \%$ respectively in function of the particle size, is really proved that the particle size is a very important fact for the mechanical behavior [27]. The decrease in elongation at break has been documented in other compounds $[25,26]$ and it is related to the imperfect interfacial adhesion between the components. Figure 5-c shows the tensile strength, in which for low GTR concentrations (5-10\%) and small sized particles, the value of tensile strength increases slightly (4-8\%), whereas for 
concentrations greater than $10 \%$, the values drop dramatically. The addition of reused tire particles in all the compounds produces a notable decrease of toughness (Figure 5-d).

\subsubsection{Mechanical behavior of PA/GTR Composites}

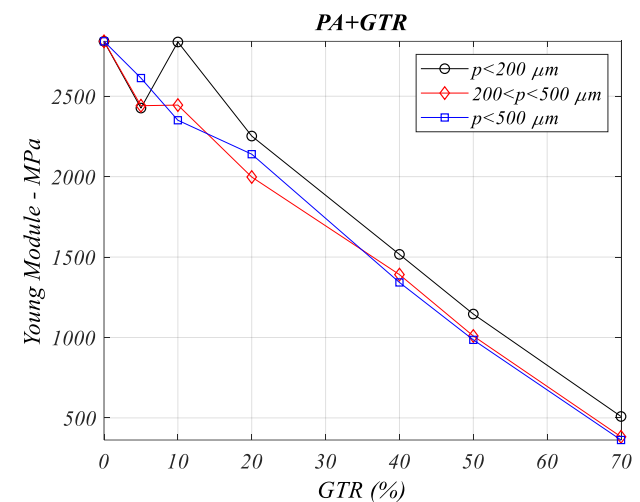

(a)

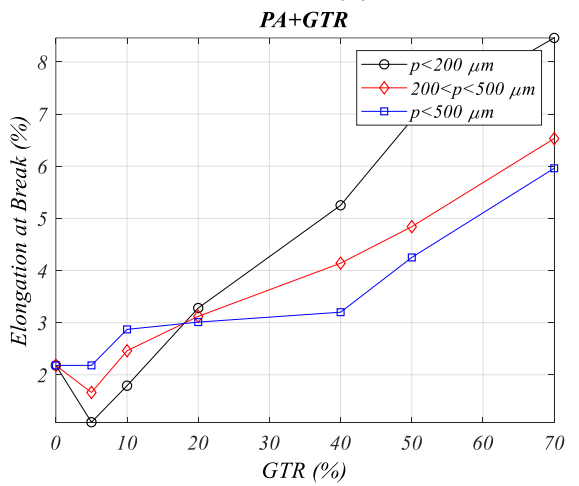

(c)

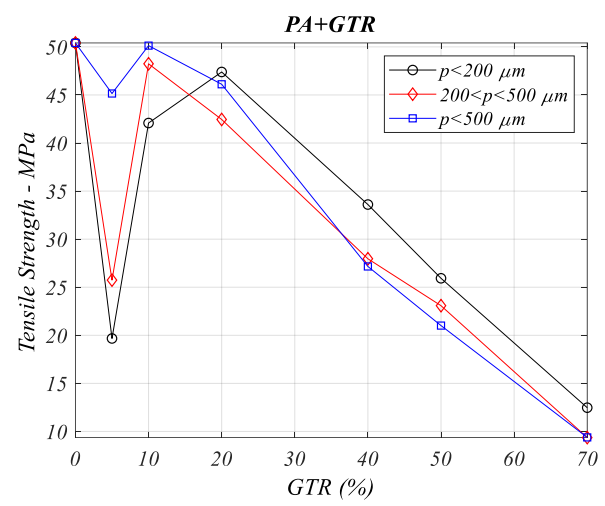

(b)

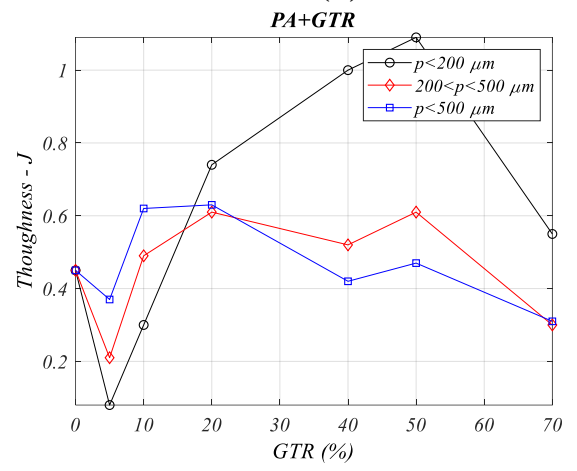

(d)

Figure 6. a) Young's modulus (MPa), b) Tensile Stress (MPa), c) Elongation at break (\%), d) Toughness $(\mathrm{J})$, for different concentrations of PA/GTR and particles sizes.

Figure 6-a shows Young Modulus of the compound, which decreases its value when adding reinforcement, compared to pure PA. The decrease is initially soft, and it becomes more significant as reinforcement is added. At concentrations of 5\% GTR, stiffness remains almost the same of pure PA (2818 MPa for pure PA vs $2715 \mathrm{MPa}$ for PA+5\%GTR, for particles with $\mathrm{p}<200 \mu \mathrm{m})$. By increasing the concentration to $10 \%$ GTR and to $20 \%$ GTR, and the same particles sizes, the decrease compared to pure PA is still weak and lower than 15\% (2600 MPa vs $2252 \mathrm{MPa}$ ). Starting from these concentrations, Young's modulus decreases significantly compared to pure PA. The so weak difference between the results obtained as a function of particle size (not more than 14\%; $1146 \mathrm{MPa}$ and $985 \mathrm{MPa}$ for PA+50\%GTR and extreme particles sizes) may be due to the internal structure of PA, which leaves open spaces. These open spaces can be filled with large size particles. This counteracts the worse adhesion of other polymers when increasing the particles size, as it causes greater likelihood of cracks. Figure 6-b shows tensile strength, where it is slightly increased with concentrations of 5\% GTR, and they decrease slowly for concentrations of 20\% GTR. So, compatibility between components is not bad for low GTR concentrations. Again, the particles size has little effect, and extreme differences are always less than $10 \%$. For this particle size $<200 \mu \mathrm{m}$, and for GTR concentrations of $40 \%$, the tensile strength decreases by $28 \%$ (32.5 MPa); and for GTR concentrations of 50\%, it decreases by $44 \%$ (26 MPa). This trend continues with higher GTR concentrations, $12.5 \mathrm{MPa}$ for $70 \% \mathrm{GTR}$ (72\% decrease).

The addition of old used tires particles in all compounds produces an increase in the elongation at break (Fig. 6-c) and in Toughness (Fig. 6-d). Thus, for particles sizes $<200 \mu \mathrm{m}$, toughness and elongation at break of GTR compounds [28] show higher values than those of the matrix of pure PA. The particles size has effect, showing an improvement for greater particle size for GTR lower than $20 \%$. Toughness has a similar pattern than elongation at brake in this case. In conclusion, PA pure is one of the worse performing tested materials concerning elongation and toughness and their properties are improved by adding GTR. 


\subsubsection{Mechanical Behavior of ABS/GTR Composites}

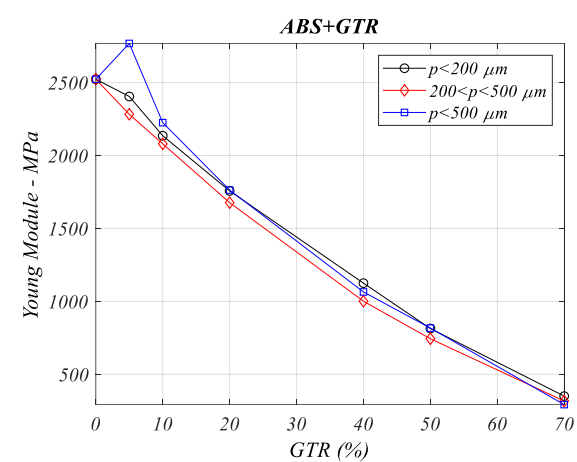

(a)

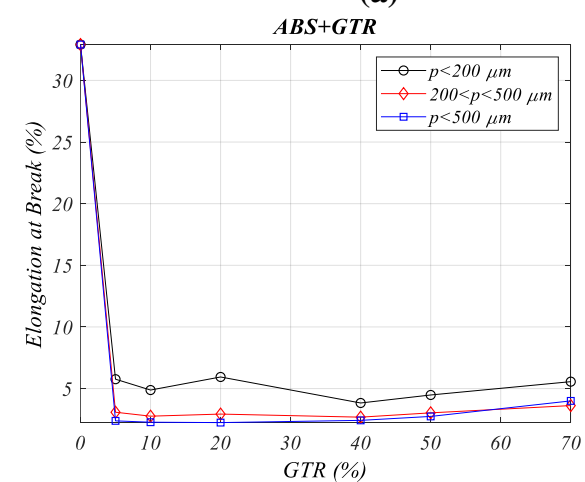

(c)

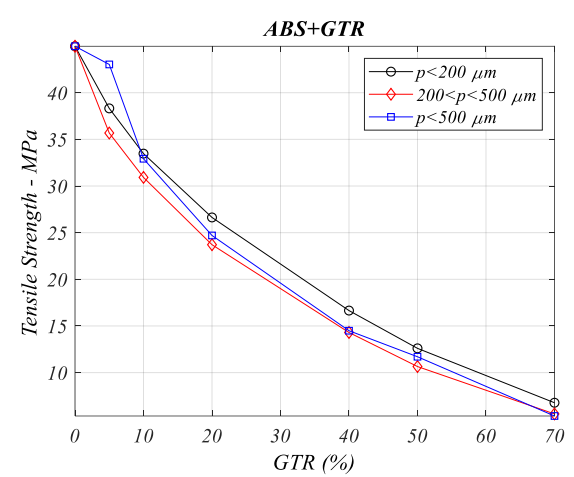

(b)

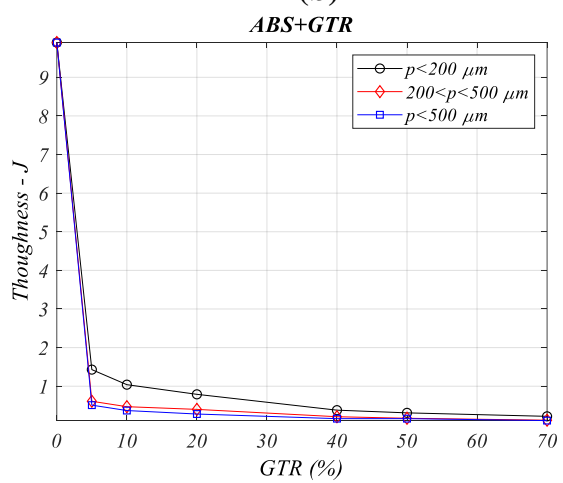

(d)

Figure 7. a) Young's modulus (MPa), b) Tensile Stress (MPa), c) Elongation at break (\%), d) Toughness $(\mathrm{J})$, for different concentrations of ABS/GTR and particles sizes.

For ABS composites it can be seen a decrease in all the mechanical properties (see Fig. 7) except for Young Modulus whose profile is shortly improved at GTR/5\% and particle $>500 \mu \mathrm{m}$. 


\subsubsection{Mechanical Behavior of PS/GTR Composites}

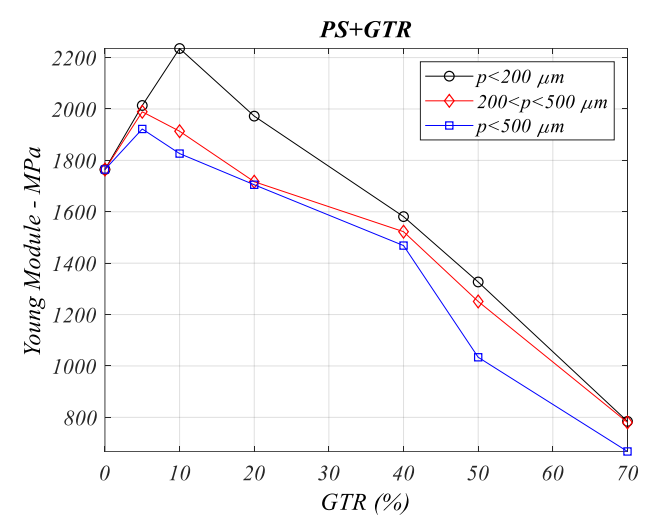

(a)

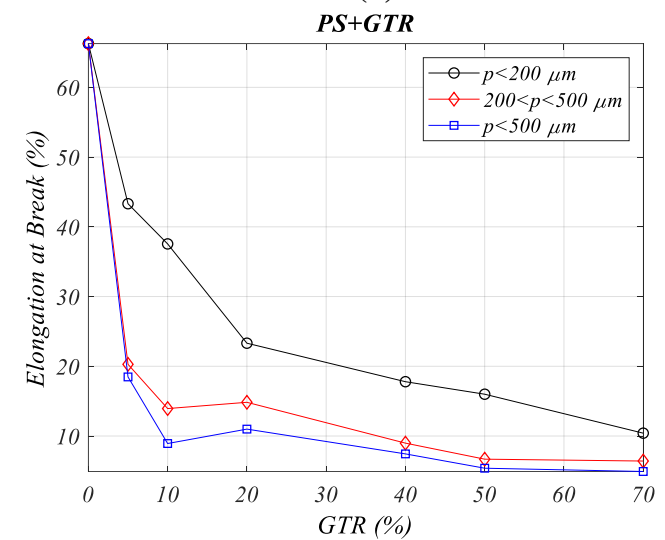

(c)

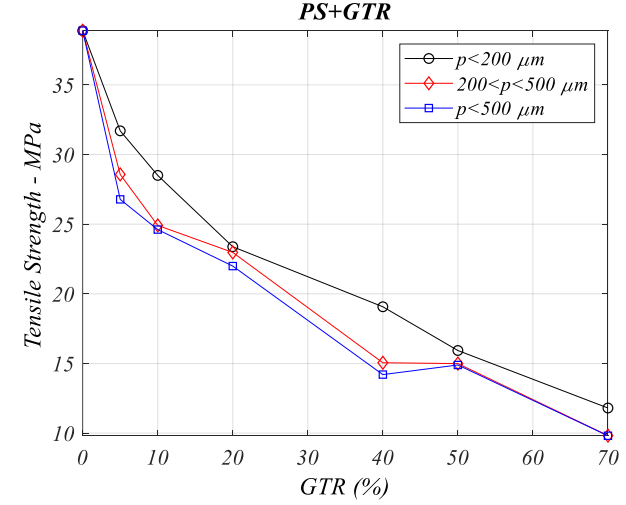

(b)

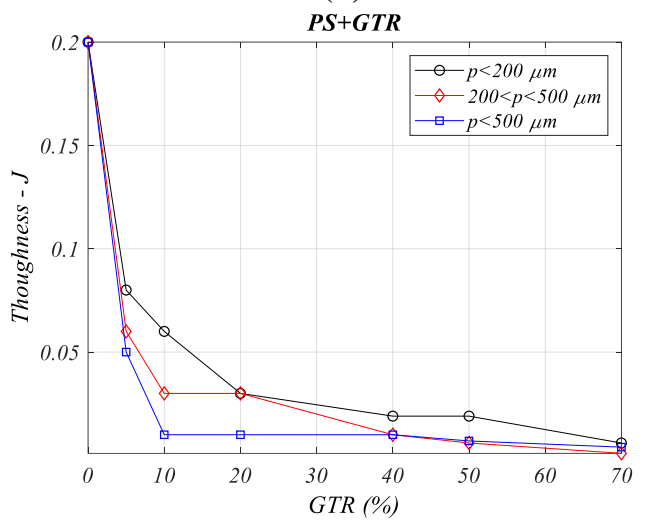

(d)

Figure 8. a) Young's modulus (MPa), b) Tensile Stress (MPa), c) Elongation at break (\%), d) Toughness $(\mathrm{J})$, for different concentrations of PS/GTR and particles sizes.

In all the mechanical properties, it's observed that all the properties are getting worse, as GTR percent increases, except for the Young Modulus (Figure 8-a) in which the addition of elastomers such as GTR causes an improvement of the PS matrix [29] for composites GTR 5-20\%. It is observed how the size of the particles are important in this case, showing better behavior the composites with lower particles sizes $(<200 \mu \mathrm{m})$. These differences obtained according to the size of the particles could be due to the fact that the PS has an internal structure that leaves open spaces, which could be occupied by larger particles. 


\subsection{Mechanical comparison results}

From the results obtained in section 2 , it can be drawn that the size particle of $p<200 \mu \mathrm{m}$ exhibits the best behavior in most of the cases analyzed. For this reason only is considered $p<200 \mu \mathrm{m}$ for the 7 polymers mixed with GTR as it is shown in Figure 9.

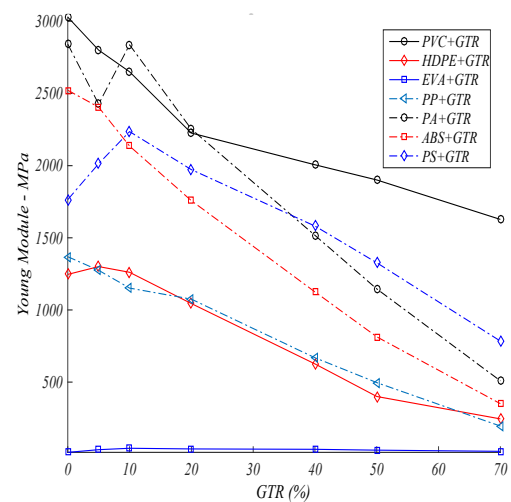

(a)

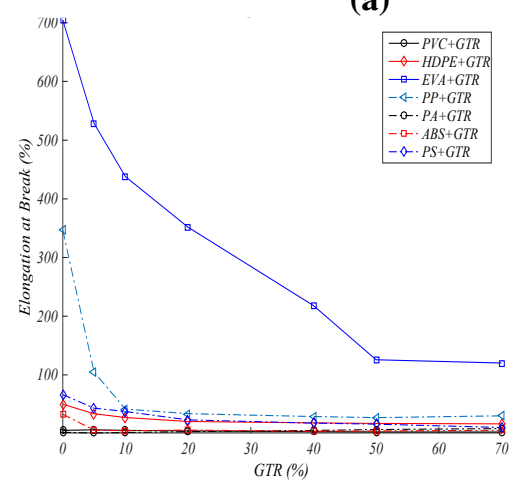

(c)

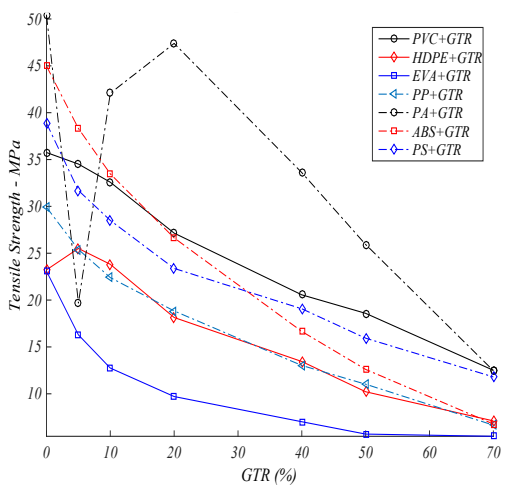

(b)

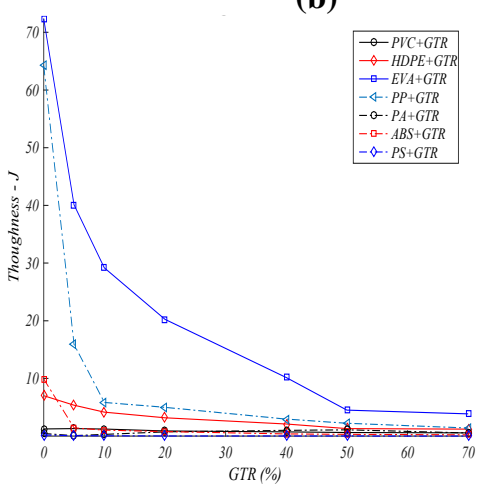

(d)

Figure 9. a) Young Modulus (MPa), b) Tensile Strength (MPa), c) Elongation at Break (\%), d) Toughness (J), for seven polymers/GTR concentrations and particle size $<200 \mu \mathrm{m}$.

For the Young Modulus (figure 9-a) analysis, we can see how the EVA, HDPE and PS compounds has better behavior with the addition of the low percent of GTR (5-10\%) in the composite. In the rest of them, generally, from the addition of GTR particles, fall the property of Young Modulus. A very prominent case is the EVA copolymer, which has lower young modulus properties (13.26MPa) and improves with the incorporation of GTR (41.67 MPa for EVA+10\% GTR). In the Tensile Strength (figure 9-b) analyzed we can see decreases more evidently for concentrations of $5-10 \%$ of GTR and higher, except for the HDPE compounds, that has better behaviors with the addition of quantities of GTR (5-10\%).

Elongation at break of the GTR compounds (Fig 9-c), the highest level of this property, clearly, is for EVA compounds, that goes from $704 \%$ to $528 \%, 437 \%$ and $351 \%$, for GTR concentrations of $5 \%, 10 \%$ and $20 \%$, and the values are always lower than pure EVA. The reduction of deformation capacity of the elastomer influences the decrease in elongation and, subsequently, the decrease of hardness, and we have similar behaviors of the Toughness property for the composites with EVA/GTR. The decrease in elongation at break is related to the imperfect interfacial adhesion between components. The rest of polymers are so low values for the elongation at break and toughness properties. The incidence of poor adhesion between phases is a particularly important result. The elongation at break property from the addition of particles of GTR, dramatically falls, but only in one case suffer a certain rises in elongation introducing percentages of GTR for PA composites, with the addition of GTR. Regarding toughness (Figure 9-d), these drops are even greater. The toughness goes from $72.3 \mathrm{~J}$ for pure EVA to $40 \mathrm{~J}$ or $29.2 \mathrm{~J}$ for $5 \%$ and $10 \%$ GTR concentrations. From the observation of the comparative graphs of Toughness (J) it can be said that of all of them those that have a greater energy to the break are: EVA, PP. The EVA polymer stands out at $72.32 \mathrm{~J}$ and, secondly, the PP polymer $(64.22 \mathrm{~J})$ is located in a very similar range of values. From the addition of GTR particles the properties of the energy at break (J) dramatically decrease. For EVA or PP adding 10-20\% of GTR, the breaking energies of the compound decrease significantly. For the PP, ABS and to a lesser extent the HDPE, the addition of GTR affects very negatively the 
properties of resistance to breakage (J), and suffer a vertiginous fall of the resistance to breakage for percentages in GTR from 5\% of GTR. A very prominent case is the polymers PVC and PA, which have very low breaking energy properties for the pure polymer, and improve this property (Toughness) with the addition of GTR percent in the matrix of that polymers.

\subsection{Discussion: Influence of GTR in the Mechanical Measurements}

In general, the addition of old used tires particles in all compounds produces a decrease in the four mechanical properties analyzed in general like young modulus (Fig 9-a) and tensile strength (Fig 9-b) elongation at break (Fig. 9-c) and toughness (Fig. 9-d). The mechanical behavior, however, is different according to particle size. For small particles, the decrease is gradual and only slightly accentuated, and its value stabilizes for concentrations of $20 \%$, whereas for medium or large sized particles, generally, the decreases of the mechanical properties are greater from the outset, and do not stabilize even with larger GTR concentrations. This behavior is due to the small particles, with low concentrations, integrating in the matrix, adding to the compound such properties as filler or polymer, whereas with larger particles, or with small particles with high concentrations, interface attachment is slight, and is the most fragile compound behavior with cracks and fractures that weaken the mechanical properties from the outset. It should be noted that, with exceptions, a better behavior of the mechanical properties analyzed are observed for samples analyzed with particles of size $<200 \mu \mathrm{m}$, followed by compounds with particles of diameters 200-500 $\mu \mathrm{m}$, and finally for particles $>500 \mu \mathrm{m}$.

The mechanical parameters are significantly influenced by the GTR. Basically, it is observed that at the mechanical levels, the properties of the pure matrix of the polymer are maintained, approximately, between 10 and $20 \%$ contribution of GTR particles (preferably of particle size less than 200 microns). The interaction of the matrix with the GTR particle is rather low, and therefore, it accepts this low content of GTR in its matrix. For values higher than $20 \%$ of GTR in the polymeric matrix, mechanical properties decrease dramatically.

Table 2. Highest values of each property analyzed and the composite regarded, size particle of GTR $<200 \mu \mathrm{m}$

\begin{tabular}{ccccc}
\hline $\begin{array}{c}\text { Polymer } \\
\text { Composite }\end{array}$ & $\begin{array}{c}\text { Young Modulus } \\
\text { (MPa) }\end{array}$ & $\begin{array}{c}\text { Tensile Strength } \\
\text { (MPa) }\end{array}$ & $\begin{array}{c}\text { Elongation at } \\
\text { Break (\%) }\end{array}$ & Toughness (J) \\
\hline$P V C / G T R$ & $3028.89(0 \% \mathrm{GTR})$ & $35.75(0 \% \mathrm{GTR})$ & $\mathbf{6 . 3 1}(\mathbf{5 \% G T R )}$ & $\mathbf{1 . 3 1}(\mathbf{5} \% \mathrm{GTR})$ \\
$E V A / G T R$ & $\mathbf{4 1 . 6 7}(\mathbf{1 0} \% \mathrm{GTR})$ & $23.08(0 \% \mathrm{GTR})$ & $704.6(0 \% \mathrm{GTR})$ & $72.32(0 \% \mathrm{GTR})$ \\
$H D P E / G T R$ & $\mathbf{1 3 0 0 . 1 1}(\mathbf{5} \% \mathrm{GTR})$ & $\mathbf{2 5 . 5 1}(\mathbf{5} \% \mathrm{GTR})$ & $50(0 \% \mathrm{GTR})$ & $7(0 \% \mathrm{GTR})$ \\
$P P / G T R$ & $1368.65(0 \% \mathrm{GTR})$ & $29.9(0 \% \mathrm{GTR})$ & $346.71(0 \% \mathrm{GTR})$ & $64.22(0 \% \mathrm{GTR})$ \\
$A B S / G T R$ & $2522.37(0 \% \mathrm{GTR})$ & $44.98(0 \% \mathrm{GTR})$ & $32.91(0 \% \mathrm{GTR})$ & $9.9(0 \% \mathrm{GTR})$ \\
$P A / G T R$ & $2841.47(0 \% \mathrm{GTR})$ & $50.41(0 \% \mathrm{GTR})$ & $\mathbf{8 . 4 6}(\mathbf{7 0} \% \mathrm{GTR})$ & $\mathbf{1 . 0 9}(5 \mathbf{5 0 G T R})$ \\
$P S / G T R$ & $\mathbf{2 2 3 5 . 4 2 ( 1 0 \% G T R )}$ & $38.89(0 \% \mathrm{GTR})$ & $66.27(0 \% \mathrm{GTR})$ & $0.20(0 \% \mathrm{GTR})$ \\
\hline
\end{tabular}

\section{Conclusions}

It can be clearly seen how the particle size decisively influences the properties analyzed, it is observed as GTR particle of lower sizes $(<200 \mu \mathrm{m})$ have better mechanical behavior, as it can be check in all the composites (Polymer/GTR) analyzed, except in the PA composites, so, the mechanical properties analyzed have a better behavior with a GTR minimum particle size $(<200 \mu \mathrm{m})$, this is due to the imperfect interfacial adhesion between components is better for a low size of particle than a highest size of particle $(p>500 \mu \mathrm{m})$. On the other hand, ccomparatively it can be deduced from the observation of the results from HDPE, PVC, EVA, PP, PA, ABS and PS with GTR, that the analyzed properties of the composites can undergo some significant changes depending on the amount of GTR that is supplied to the polymeric matrix, that is, some important properties vary according to the percentage of GTR contributed. As it can be seen in the Table 2, mainly, the highest values of property are corresponding to the pure polymer ( $0 \%$ GTR), with some important exceptions as are highlight in the table, so for EVA, HDPE, PA and PS some mechanical properties are improved by the addition of micro particles $(<200 \mu \mathrm{m})$ of GTR in the matrix of the polymer. Ading the GTR in the matrix (5-10\%), and especially for small particle sizes, the 
Young's Modulus of the compound increases, although other mechanical properties decrease it happens with the EVA, PS and HDPE composites, for the rest of the cases the Young's Modulus get worse. This behavior may be due to the fact that reinforcement-matrix is correct for these formulations, and therefore, some mechanical properties such as stiffness improve. However, for GTR concentrations above $10 \%$, with any particles size, all mechanical properties decrease, except for PA composites, and the larger size of the particle is, the more significant the decrease is. The results obtained from the analysis of these compounds, show that that at $5-10 \%$ GTR concentration is the limit concentration value for keeping acceptable values of mechanical properties of the compound, in general. This would allow its use in various fields of industry, through these applications we could introduce recycled GTR in industrial applications, and so we could give also an exit to quantities of GTR in disuse that nowadays represent a problem its recycling, other works [30-35] gives an effort in this way and this research work pretend to give an effort in the characterization field of the composites with GTR.

Author Contributions: The individual contribution of each author is: Introduction, Abstract and Methodology: Marc Marín-Genescà, Graphs, Results and References: Jordi Garcia-Amorós and Xavier Salueña-Berna, Conclusions:

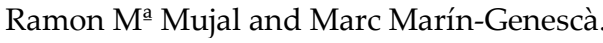

Funding: This research was funded by the MINISTERIO DE ECONOMIA Y COMPETITIVIDAD, Gobierno de España ENE2015-64117-C5-3-R (MINECO/FEDER).

Acknoledgements: This work was funded by the Ministerio de Economía y Competitividad de España ENE201564117-C5-3-R (MINECO/FEDER).

Conflicts of Interest: The authors declare no conflict of interest.

\section{References}

[1] European Tyre Recycling Association (ETRA). Available at: www.etra-eu.org.

[2] Used Tyre Working Group (UTWG). Tyre Recycling; Department of Trade and Industry: London, UK. Available at: www.tyredisposal.co.uk, November 2006.

[3] Liu HS, Richard CP, Mead JL and Stacer RG. Development of Novel Applications for Using Recycled Rubber in Thermoplastics; Technical Research Program, Chelsea Center for Recycling and Economic Development, University of Massachusetts: Lowell, 2000.

[4] Figovslq O, Beilin D, Blank N, Potapo J and Chernyshe V. Development of polymer concrete with polybutadiene matrix. Cem Concr Compos 1996, 18, 437-444.

[5] Hernandez-Olivares F, Barluenga G, Bollatib M and Witoszekc B. Static and dynamic behaviour of recycled tyre rubber-filled concrete. Cem Concr Compos 2002, 32, 1587-96.

[6] Goncharuk GP, Knunyants MI, Kryuchkov AN and Obolonkova ES. Effect of the specific surface area and the shape of rubber crumb on the mechanical properties of rubber-filled plastics. J Polym Sci Part B: Polym Chem 1998, 40, 166-169.

[7] Dierkes WK. Rubber recycling. In Recent research developments in macromolecules, Pandalai SG, Ed.; Trivandrum: Research Signpost, 2003, vol. 7, pp. 265-292.

[8] Radeshkumar C and Karger-Kocsis J. Thermoplastic dynamic vulcanisates containing LDPE, rubber, and thermochemically reclaimed ground tyre rubber. Plast Rubber Compos 2002, 31,99-105.

[9] Yehia A, Mull MA, Ismail MN, Hefny YA and Abdel-Bary EM. Effect of chemically modified waste rubber powder as a filler in natural rubber vulcanizates. J Appl Polym Sci 2004, 93, 30-36.

[10] Colom X, Andreu-Mateu F, Cañavate FJ, Mujal R and Carrillo F. Study of the influence of IPPD on thermo-oxidation process of elastomeric hose. J Appli Polym Sci 2009, 5, 2011-2018. 
[11] Cepeda-Jimenez CM, Pastor-Blas MM, Ferrándiz-Gómez TP and Martín-Martinez JM. Surface Characterization of vulcanized Rubber treated with sulphuric acid and its adhesion to polyurethane adhesive. J Adhesion 2000, 73, 135-160.

[12] Mujal R, Marín-Genescà M, Orrit J, Rahhali A, Colom X, Dielectric, mechanical, and thermal characterization of high-density polyethylene composites with ground tire rubber. Journal of thermoplastic composite materials, 2012, vol. 25, núm. 5, p. 537-559

[13] Mujal, R.; Orrit J., Ramis, X.; Marin-Genesca, M.; Rahhali, A. Study on dielectric, mechanical and thermal properties of polypropylene (PP) composites with ground tyre rubber (GTR). Polymers \& Polymer Composites (ISI), Polymers \& Polymer Composites, Vol. 20, No. 9, 2012

[14] Marin-Genesca, M.; Mujal, R. Compuesto etileno acetato de vinilo (EVA) reforzado con neumáticos fuera de uso (GTR) propiedades dieléctricas, mecánicas y térmicas. Afinidad. Vol 71, No 566 (2014).

[15] Marin-Genesca, M.; Mujal, R.; Orrit, J. Características dieléctricas, térmicas y mecánicas de la poliamida (PA) reforzada con neumáticos fuera de uso. 2013 Article. Afinidad: Revista de química teórica y aplicada, ISSN 0001-9704, Vol. 70, 561, 2013, pag. 13-23

[16] Marin-Genesca, M.; Mujal, R.; Ramis, X. Aplicaciones dieléctricas del poliestireno (PS) cargado con neumáticos fuera de uso (GTR). Revista DYNA, ISSN 0012-7361, Vol. 88, № 6, 2013, págs. $652-662$

[17] Mujal R, Orrit-Prat J, Ramis-Juan X, Marin-Genesca M, Ahmed Rahhali. Dielectric, Thermal, and Mechanical Properties of Acrylonitrile Butadiene Styrene Reinforced with Used Tires. Advances in Polymer Technology 32:E399-E415. Wiley 2013. 0730-6679

[18] Mujal, R.; Ramis, X.; Orrit-Prat, J; Marin, M.; Study on dielectric, thermal, and mechanical properties of the ethylene vinyl acetate reinforced with ground tire rubber. Journal of Reinforced Plastics and Composites 30(7):581-592 - April 2011. DOI: 10.1177/0731684411399135

[19] Mujal R, Orrit-Prat J, Ramis-Juan X, Marin-Genesca M. Electrical application of polyamide reinforced with old tire rubber (ground tire rubber): Dielectric, thermal, mechanical and structural properties. Journal of thermoplastic composite materials. 27(9):1209-1231. 2014. 0892-7057

[20] Nakason C, Kaesaman A and Supasanthitikul P. The grafting of maleic anhydride onto natural rubber. Polym Test 2004, 23, 35-41.

[21] La Mantia FP, Lo Verso S and Tzankova Dintcheva N. EVA Copolymer Based Nanocomposites. Macro Mat Eng 2002, 287, 12, 909-914.

[22] Kim JI, Ryu SH and Chang YW. Mechanical and dynamic mechanical properties of waste rubber powder/HDPE composite. J Appl Polym Sci 2000, 77, 2595-2602.

[23] Markov A., Fiedler B., Schulte K. Electrical conductivity of carbon black/fibres filled glass-fibre-reinforced thermoplastic composites. Composites Part A: Applied Science and Manufacturing

Volume 37, Issue 9, September 2006, Pages 1390-1395

[24] Saad ALG, Aziz HA and Dimitry OIH. Studies of Electrical and Mechanical Properties of Polyvinyl chloride) Mixed with Electrically Conductive Additives. J Appl Polym Sci 2004, 91, 1590-1598.

[25] Ganesh B and Unnikrishnan GJ. Cure characteristics, morphology, mechanical properties, and aging characteristics of silicone rubber/ethylene vinyl acetate blends. Appl Polym Sci 2006, 99, 3, 1069-1082.

[26] Colom X., Cañavate J., Carrillo F., Structural and mechanical studies on modified reused tyres composites. Eur Polym J 2006; 42: 2369-2378.

[27] Kim JI, Ryu SH and Chang YW. Mechanical and Dynamic Mechanical Properties of Waste Rubber Powder/HDPE Composite. J. Appl. Polym. Sci 2000; 77: 2595-2602.

[28]M. Vesenjak, L. Krstulović-Opara, Z. Ren, Ž. Domazet. Cell shape effect evaluation of polyamide cellular structures. Polym Test 2010;29(8):991. 
[29]. Zhang W, Zhang Y, Zhang G. Static, dynamic mechanical properties and microstructure characteristics of ultra-high performance cementitious composites. Science and Engineering of Composite Materials, 2012; 19(3); 237-245. (DOI: 10.1515/secm-2011-0136)

[30] Cheng X., Chen H., Huang S., Li Z., Guo X.. Improvement of the properties of plasmamodified ground tire rubber-filled cement paste. Journal of Applied Polymer Science. Volume 126, Issue 6

[31] Formela K., Cysewska M., Haponiuk J. T.. Preparation of rubber composites from ground tire rubber reinforced with waste-tirefiber through mechanical milling. Journal of Vinyl and Additive

TechnologyVolume 22, Issue 3. First published: 29 July 2014

[32] Formela K., Haponiuk J.. Characterization and properties of LDPE/(ground tire rubber)/crosslinked butyl rubber blends. Journal of Vinyl and Additive Technology. Volume 20, Issue 4. First published: 28 May 2014

[33] Nadal A., Boix M., Parres F., Agud L., Crespo J. E., Macías-García A.. Modelling the compression behavior of ground tire rubber. Materialwissenschaft und Werkstofftechnik. Volume 47, Issue 4. First published: 09 April 2016

[34] Marín-Genescà, M.; García-Amorós, J.; Mujal-Rosas, R.; Vidal, L.M.; Arroyo, J.B.; Fajula, X.C. Ground Tire Rubber Recycling in Applications as Insulators in Polymeric Compounds, According to Spanish UNE Standards. Recycling 2020, 5, 16.

[35] Marín-Genescà, M.; García-Amorós, J.; Mujal-Rosas, R.; Massagués, L.; Colom, X. Study and Characterization of the Dielectric Behavior of Low Linear Density Polyethylene Composites Mixed with Ground Tire Rubber Particles. Polymers 2020, 12, 1075. 